\title{
PRODUCING KNOWLEDGE ABOUT 'THIRD WORLD WOMEN': THE POLITICS OF FIELDWORK IN A ZIMBABWEAN SECONDARY SCHOOL
}

Abstract: Fieldwork is a project in which 'researcher, researched and research make each other' (Rose, 1997, p. 316), yet far more attention has been given to the making of the research and researcher than to the researched. Focusing on three aspects of the research process (the researcher's presence in the field, research topic and choice of methods), this paper uses examples from the author's own fieldwork to debate whether it is possible to shape fieldwork such that the knowledges created and consumed in the field by the researched serve to destabilise dominant discourses of race, gender and age.

\section{Introduction}

Much methodological literature has considered the influences of fieldwork on textual productions or on researchers themselves (for recent examples, see Shah, 1999; Twyman et al., 1999; Widdowfield, 2000). Fieldwork's influences on the researched have received less attention. This perhaps reflects a reluctance to claim to 'know' the researched. However, given that we cannot claim perfect self-knowledge (Rose, 1997), and continue, in other genres, to make knowledge claims about research subjects, it seems appropriate to speculate on fieldwork's effects on the researched.

In 1997 I undertook fieldwork in a rural secondary school in Zimbabwe to explore ways in which secondary education facilitated the production of new discourses about gender among young Zimbabweans. To produce 'knowledge' (about changing gender relations in Africa) for presentation in a PhD thesis (Ansell 1999), I sought to uncover processes of knowledge production (about gender relations in Africa) taking place in school. Consequent on my being in the field, further knowledge was created. The latter of these three related processes - the production (and consumption) of knowledge by the young research subjects and their teachers through the fieldwork encounter - is considered here.

My research within the school focused on the experiences of young people, particularly girls. Conducting fieldwork as a white, First World, ${ }^{1}$ female, (postgraduate) academic among teenage girls in a Zimbabwean school raises a number of ethical dilemmas. These arise in particular because of the subordination of the schoolgirls through relations of gender, age, and race/global political economy, axes of subordination considered in methodological literatures from three areas of geography: feminist geographies, geographies of youth and postcolonial geographies. Work from all three perspectives problematises two areas of the 
research process: the textual representation of the researched to an (academic) audience and the politics of the research encounter itself. With few exceptions (e.g. Mohan, 1999; Nast, 1994; Rose, 1997), the two areas have remained conceptually separate. This paper brings together both areas of concern, to focus on fieldwork as a process of knowledge representation and production which takes place in the field: where the researched are (unavoidably) co-producers of, and an audience for, the production of new knowledge about (among other things) Third World women and girls.

\section{Representation}

Concern over representation has focused on the discursive effects of textual representations of the researched (e.g. Staeheli and Lawson, 1994) and on the question of who can legitimately (re)present the 'other' (e.g. Kobayashi, 1994; McDowell and Sharp, 1997; Nast, 1994; Radcliffe, 1994). Critical of Western epistemology that casts women, young people and colonial 'others' as inferior and passive, scholars have stressed the importance of enabling the voice of the 'other' to be heard (e.g. Donovan, 1988; McDowell and Sharp, 1997; Ramazanoglu, 1992). Researchers, however, cannot act as neutral conduits for the authentic voice of the marginalised, which is inevitably mediated through the research process and decisions made in the construction of texts. While important, these debates neglect processes of giving voice in the field itself. A researcher not only represents the researched to a distant audience, but represents that 'distant other' to the researched. Questions of who 'we' represent, and how our representations of 'ourselves' are consumed in the field, have received minimal attention. In considering fieldwork as an act of giving voice, of representing ('us'2 and 'others') through our actions and interactions in the field, issues of essentialisms, universalisms, partiality and insider/outsider status demand further consideration.

\section{Politics of the Research Encounter}

Those concerned with the researcher's presence and actions in the field have highlighted a different set of issues: the disruption researchers cause to the lives of people marginalised through exploitative power relations (England, 1994), and whether research with marginalised people is justified if made possible only through relations of exploitation (Madge, 1993). However, we cannot remove ourselves from a world economy in which we benefit from exploitation that takes place out of our sight (Corbridge, 1998). There is a need to move beyond debates concerning the overall project of fieldwork, which essentialise and bound the activity, casting it as either good or bad. The field itself is not bounded (Katz, 1994), nor is the research encounter an event separate and distinct from everyday life (Katz, 1992; Varley, 1996). The pertinent task, then, is to consider the details of fieldwork and the impacts of various aspects and forms of research. 
Some researchers have sought to make the research encounter less exploitative. Research has sometimes been envisaged as a transaction: in return for 'data-mining' (Chambers, 1983), the researcher should 'give back' to the researched. Monetary payment or material gifts, however, cannot be removed from the unequal economic power relations that enable them. Teaching, sometimes seen as a way of balancing the research encounter (Pollard, 1985), is even more problematic, suggesting the researched would benefit from 'superior' Western knowledge. Feeding back research findings to the participants, without consideration to the form of the feedback, may mean little to the researched (Matthews et al., 1998).

Given the impossibility of an equal transaction, free of exploitation, some researchers advocate contributing to a modification of the power relations through which the researched are subordinated. This, too, is problematic. 'Consciousness-raising', for example, relies on a shared subject position between researcher and researched (Gibson-Graham, 1994). Once essentialist categories are rejected, the Western background of the consciousness-raiser carries the same colonialist overtones as teaching. "Women with whom one is working may not share the (same) feminist agenda and the question must be asked whether the researcher is justified in imposing their agenda on the "researched" (WGSG, 1997, p. 93). Patai argues 'to turn interviews with other women into opportunities for imposing our own politically correct analyses requires an arrogance incompatible with genuine respect for others' (1991, cited in Gilbert, 1994, p. 98). Even aiming to empower the research subject can assume a relation of domination (McDowell, 1997).

The field is not, however, a scene apart from the discourses of age, race and gender through which power is exercised. The researcher cannot perform a neutral role, but inevitably participates in the (re)production of power relations in the field. Working from a position that to contribute to the subordination of the researched should be avoided as far as possible, a way to avoid exploitation might be to attempt to 'manage' the research encounter such as to promote the destabilisation of dominant discourses of race, gender, age, etc. and facilitate the production of new oppositional discourses. This paper assesses how far such a strategy is possible, by addressing three areas of the fieldwork process: the researcher's embodied presence in the field, the topic of research and the choice of research methods. First, however, it puts into theoretical context the role of the researcher in the construction of knowledge through the research process. 


\section{Joint Production of Knowledge}

Given a conception of power as exercised, in part at least, through discourse, no research encounter can leave the researched powerless. Research subjects may exploit the encounter to serve their own agendas: they are active social agents (James et al., 1998; Matthews et al., 1998; Valentine et al., 1998), constantly engaged in (re)producing knowledge. The researched inevitably engage with identities created for them in the field. Gibson-Graham sees 'social research as a public engagement in the construction of alternative discourses' (1994, p. 215). New discourses contributing to the destabilisation of existing discourses are jointly produced by researcher and researched in the course of the research process and 'may have long lasting effects upon thought and action' (Gibson-Graham, 1994, p. 220), including in the field.

The links between power, ethics and knowledge (Madge, 1994) have inspired suggestions of collaborating in knowledge production with Third World academics, while the difficulties of such collaborations are also acknowledged (e.g. Batterbury, 1994; Porter, 1995; Radcliffe, 1994; Sidaway, 1992). The purpose is partly to '[open] up 'spaces' to contest (Eurocentric) accepted systems of knowledge' (Madge, 1993, p. 296) and to 'challenge notions of gender relations in the Third World, as well as to create new authoritative stories in dialogue, in communication with the south' (Radcliffe, 1994, p. 29). However, the focus has been on collaborating in producing knowledge with Third World academics, rather than with 'ordinary' people.

Should the research product in the field (the production of new knowledge among the researched) be understood in the same way as we understand a written text? Nast urges us to 'confound the distinction commonly placed between 'the politics of fieldwork' and 'the politics of representation" (1994, p. 60), emphasising the multidimensional web of communication between researched, researcher, text and audience. However, while the research encounter is itself an act of representation, and the field and academy are not fundamentally distinct, knowledge production in the field among research subjects differs from the textual product delivered within the academy. Nast herself acknowledges the 'material differences in the durée of space-as-texts and literary texts' and the different material and political interests and forces involved (1994, p. 61). The power relations of the field, and embodiedness of the researcher in that field mean that the researcher has far less control over knowledge production for, and its reception by, those in the field (see Nast, 1998; Rose, 1997). As Stacey points out, critical ethnographers 'perceive their subjects as collaborators in a project the researcher can never fully control' (1997, p. 119). Although she claims that 'the research product is ultimately that of the researcher, however modified or influenced by informants' 
(p.118), this is only clearly true of the textual product. The extent to which the researcher can take responsibility for the product jointly produced and consumed in the field is debatable.

\section{Knowledge and Transparency}

Lack of control over the research product in the field relates in large part to the complexity of that field. Sidaway (1992, p. 405) reminds us 'research is part of the social world it studies. That social world is profoundly uneven and contradictory.' Furthermore, the power relations of the field, and the role played by the researcher in it are not fully knowable. Rose $(1997$, p. 311) is critical of what she terms 'transparent reflexivity' which 'depends on certain notions of agency (as conscious) and power (as context), and assumes that both are knowable'. Through lack of understanding, 'outsider researchers may unwittingly help to reinforce broader relations of domination and oppression within the society in question' (Smith, 1994, p. 363).

Rose (1997, p. 317) asserts, however, that 't $\mathrm{t}$ he negotiations that are part of a research process are not fully knowable; the effects of an interview, a publication, a presentation, are impossible to predict. This impossibility does not absolve researchers from the obligation to work in an ethical manner.' This raises the question, not addressed by Rose, of how a researcher might 'work in an ethical manner'.

While transparent reflexivity may be an impossible 'goddess-trick', it is not possible to engage in ethical research without some form of critical reflection upon the effects one's research has on others. While the contexts of the research can never be fully knowable, there is a need to engage in an exploration of the effects of the researcher's presence and actions in and on the field. To achieve this, the researcher must explore, not only the power relations sustaining the researcher's position in the field, but the relations between actors in the field. According to Stacey (1997, p. 120), '[t]he majority of feminist claims about feminist ethnographic and other forms of qualitative research ... presume that such research occurs almost exclusively woman-to-woman.' There is a need to address wider social relations. Those researching with children have more consciously considered relationships of their research subjects to adults (James et al., 1998; Valentine, 1999) and peers (Caputo, 1995) and the effects of these on the ways research affects the researched.

Knowledge is not produced by the individual observer in isolation, but through discourse. It is therefore necessary to give attention to the locally inflected, varied and fluid discourses of gender, race and age that 
already exist in the researched community and the ways researchers slot into/are slotted into these. (The two are not entirely independent, and are also related to social class and urban-rural hierarchies, neither of which are considered here for want of space.) Discourses intersect in ways that are often contradictory, making the intervention of the researcher into the field particularly problematic.

\section{Empirical Context}

The research was conducted in a 'typical' rural district council day school in Manicaland, attended by about 500 students, aged 13-20, from a rural catchment that depends economically on subsistence agriculture and male labour migration. While most teachers held teaching qualifications, the school was poorly resourced, lacking electricity or running water and having few books or materials. Pass rates in public examinations were poor and few children succeeded in entering the formal sector labour market upon leaving school.

As a field for research, the school was implicated in multiple power relations. In the global context, formal schools were introduced to Zimbabwe in colonial times, and are still imbued by colonial practices of power, presenting and validating Western 'ways of knowing'. ${ }^{3}$ As such, they might reasonably be considered instruments of colonial domination, albeit having been modified in the post-independence era, and also expressing the extension of state power into rural areas. Internally, schools are profoundly hierarchical. Discourses of gender, race and age prevalent in school are varied and contested, but elevate Western knowledge (through internationally published textbooks, UK-validated public examinations etc.). Age is understood to accord privileges, and while education is in some degree seen as equally available to either sex, girls are fewer in number, less successful academically and required to perform chores not demanded of boys. Gender discourses further reflect the dominance of men in the teaching hierarchy. It was these discourses, which accord status on the basis of age, gender and global political economy, that I sought to destabilise rather than reinforce through my part in the joint production of knowledge.

\section{Embodied Presence in the Field}

While a researcher generates 'data' through fieldwork, the researched, too, produce knowledge through the researcher's bodily presence in the field and through their bodily performance in that field. As an embodied researcher, I enter the field marked by such attributes as age, gender and skin colour - all of which are constructed in particular (and varied) ways by the researched. These are pre-inscribed, cannot be disguised and influence the ways the researched read the fieldwork process. Consequently, one's body represents more than oneself. For the researched it represents wider relations of domination. 
A researcher's presence in an African country is arguably evidence of conquest, of the West's 'mastery' over African space: their existence in the field exposes/constructs knowledges of power relations. Presence in school also promotes the construction of knowledges about the researcher (as, in my case, an educated white woman, and inferentially about education, race and gender); about (the) school; and about the young people attending the school. While presence in school perhaps tells students they are important, students might use this presence to reinforce discourses that revere the school as institution, the value of the (Western) knowledge imparted there, and that denigrate the agency of youth. In my research, I unavoidably represented both the First World (and the power of the First World in relation to Zimbabwe) and women (or at least some fraction of that part of society that Zimbabweans construct as 'women'). This is not to suggest that I am the only image of 'First World woman' available to the researched, but I am an embodied image and am read, partly in relation to other images.

Bodily presence is not, however, prior to performance: while a researcher, in order to research, has little option with regard to the former, they have a degree of control over the latter. Literature concerned with ethnographic research focuses on the need for the researcher's behaviour in the field to conform broadly to the social behaviours of the researched, to show respect and facilitate acceptance. At the same time the researcher is advised to maintain 'critical' distance and avoid 'going native' to achieve a degree of objectivity. This view sees the researcher as an individual - perhaps not a disembodied observer, but a disconnected body - disconnected from the power relations that support their existence and actions in the field. Researchers are not, however, disconnected. Although the selves researchers present are inevitably bounded (Katz, 1992), as texts, bodies are not hermetically sealed, but point beyond themselves (cf. Fischer, 1986, cited in Keith, 1992). We 'stage' the world (Spivak, 1988) in our performance in the field. Bodily presence in the field may enable the researcher to perform behaviours that disrupt dominant discourses. Through bodily comportment one can (within limits) conform to or confound dominant knowledges. This is not, however, a simple question of conforming to or rejecting dominant modes of behaviour.

Those writing about the representation of others have endeavoured to negotiate boundaries of 'difference' and 'equality' (see Bondi in WGSG, 1992; WGSG, 1997). Difference is also constituted within the research process (Rose, 1997). Nast (1998, p. 107) points out, in relation to fieldwork, that 'the body is itself a field for registering and negotiating difference.' In considering the representation of ourselves in the field, researchers must then confront the question of how we constitute difference through the research process: should we 
perform 'difference' or 'equality' and in relation to whom? Rose points out, however, that difference is not the same as separation; nor is it the converse of equality, but both are mutually constituted.

The constitution of difference/equality, and its problematic relationship with the production of counter discourses, can be illustrated by reference to examples from my field experience. Living on the school campus entailed drawing water from a borehole 500 metres from my house. This was one of the more arduous aspects of teaching in a rural school, and the headteacher allowed teachers to send students to the borehole in their lunch hours to collect their daily supply of water. In conformance with Zimbabwean expectations of gendered behaviour, girls were invariably sent on this difficult and time-consuming task.

Lacking the physical skill to carry 20 litres of water on my head, I, like the teachers, asked students to assist me. Like the teachers, I refrained from asking boys. However, for the week my partner was present in the field, he fetched the water, his behaviour, arguably, a Western masculine display of physical strength. He also washed dishes and clothes in public outside the house, activities which contravened expectations of gendered behaviour in Zimbabwe. Many Zimbabweans would mark such a man as weak and effeminate and his wife as immoral or bad. In other ways I conformed to gender stereotypes, refusing to drink at the beer halls, and returning before dark to the campus in the evenings. I thus performed both 'difference' (from female teachers on the campus and from students) and 'equality' (with female teachers, and, at times, with male teachers). Neither is unproblematic in its possible influences on the production of knowledge by the researched.

Conforming to the cultural practices of our research subjects, or 'falling into' (Nast, 1998) their behaviour, may signal approval of their ways of living, even when we (and possibly they) see exploitative power relations underlying these practices. In using female students to collect water, I participated in (and exploited) relations of domination associated with age and gender. Performing equality also contributes to the creation of knowledge about subordination. If I imply there is no difference between myself and the researched (beyond those that cannot be disguised), I deny the power relations that create that difference. This raises the question of whether I should make explicit the power relations that contribute to my part in the construction of knowledge in the field. Should I confirm (through the way I dress, behave and speak) the prevalent view among the researched that England is very rich (which it is, relative to Zimbabwe), a wealth based partly upon (colonial and neo-colonial) economic exploitation of Africa, thereby assuming the role of 'oppressor'? Or should I disguise my personal (relative) affluence and point to the poverty and homelessness 
in England, so as to reduce the perceived difference between us? Madge confronted similar questions during fieldwork:

Rather than acknowledging my 'whiteness', the fact that I was from 'there' and that I was 'rich', I wished to obscure these things, to shroud my (material) power, and to wish away the historical relations that surrounded it. In other words, I tried to ignore the political economy of power relations (Madge, 1994, p. 97).

Ultimately, difference exists in our bodies in ways we cannot disguise - in (socially constructed) skin colour and in different abilities to perform particular behaviours, including acquired skills such as carrying water. It might seem that researchers should deliberately perform difference. Apart from making global power relations explicit, we might demonstrate to the researched that there are alternative ways of living. However, performing difference is also problematic. In engaging in unfamiliar activities (such as an egalitarian division of domestic chores) I might be seen simply as foreign, an 'honorary man', whose different behaviour says nothing about gender relations in the Zimbabwean context. Although no one commented specifically on my behaviour, many remarked that Western men were 'different' from African men, and that gender relations in Zimbabwe were thus inevitably different. To produce (jointly with the researched) a representation of 'First World woman' as an essential and particular category undermines possibilities for productive dialogue or the production of empowering discourses.

Alternatively, my 'difference' might be interpreted in more universalist ways. By 'performing difference', I risk implying that (I think) my ways are 'better': that I see myself as a role model for Zimbabwean women, having, as a Western woman, progressed further along a universal path towards equality. As such, I might be seen, either as a desirable role model, or as bearing a threat of cultural pollution, introducing undesirable Western ways, a vector of colonialism. The undesirability of either scenario is clear.

Regardless of the difficulties associated with 'difference' or 'equality', in practice researchers (inevitably) perform both difference and equality - we are neither absolute insiders or outsiders among the researched community. Through our 'betweenness', difference and identity subvert one another (Katz, 1992). Arguably, we should negotiate between difference and equality, avoiding essentialist or universalist (re)presentations of/through ourselves, but emphasising our connectedness. Hence we might demonstrate the diversity of 
ways of living available to women, while acknowledging that all women are constrained in varying ways through particular relations of domination.

Avoiding closure in representations of oneself is not an easy task. Clearly, it is impossible as an individual woman to represent the diversity of gender relations in the West. We can, however, to some extent reveal the power relations to which we are subject, in part through how we act, in part through the stories we tell. We need, however, to acknowledge that we do not create stories in isolation, but with the researched. Research subjects are frequently curious to hear of our ways of living, but we cannot control the interpretations they will make of our lives. The most we can do is offer women stories about us that they can use in the construction of new oppositional discourses.

\section{Research Topic}

My presence in school itself suggested an interest in young people and schooling. While not (for purposes of generating useful 'data') explaining my research in detail, I did reveal that I was interested in girls' experiences and gender relations. While the researched may have read from this that gender is significant and girls' experiences important, my positioning as a white Western woman carried two risks. First, it could reinforce the idea that 'woman' is a universal category. At the same time, it may reinforce the prevalent belief among Zimbabweans that gender is an interest of Westerners, particularly women, and need not, therefore, concern them. It even risked facilitating the construction of interest in gender as emblematic of neo-colonial interference in African culture. Certainly, the subject of my research generated no surprise among the researched, and some teachers expressed resentment at my focus on girls.

\section{Choice of Methods}

To generate data I engaged in a variety of activities in the field, beyond those of daily living. Through these the researched also produced knowledge about the power relations supporting my position in the field, as well as about the power relations of the field itself. Below, four methods of data generation are discussed and their relation to discourse production by the researched compared.

\section{Participant Observation}

In accessing a school, my preference was to negotiate with headteachers, rather than being imposed upon a school by education ministry officials. I chose to adopt a stance of supplication, not because this allows power to be shifted away from the researcher (England, 1994), a view which envisages power as context 
(see Rose, 1997), but because accepting a stance of dependence stresses the value of the knowledge of the researched. Consequently, I set out in my research with a position in the school clearly subordinate to the headteacher. Ironically, my freedom to resist the discourses that accorded me status on the basis of age, race and education was constrained by my obligation to a headteacher who expected me to behave like a teacher. Our bodies are 'placed' in the field by the researched in ways we cannot readily control (Robson, 1994). Nast describes entering 'positionings I did not recognise as my own and that occurred despite my intentions and reflections' (1998, p. 108).

Authority within the school was not static or unchallenged. The headteacher's absence through illness at the start of term provoked a contest to replace him, giving rise to new dynamics, and a different position for myself within the school hierarchies. Neither (male) protagonist had directly sanctioned my position in the school, both were younger than me, and had known me as an 'equal'. Although I avoided 'taking sides', both teachers tried to use my presence to bolster their power. When, for example, inspectors visited the school in response to a student strike (another attempt at destabilising power in the school), I was presented by the then acting head as an important international visitor. On another occasion, the headteacher returned briefly to the school to address the teachers. The five student teachers on the staff were excluded from the meeting on the basis that they were stirring trouble. I was beckoned by the head to leave with them. In this instance, my status was lowered with that of the student teachers, condemned to stand in the sun under the gaze of the abandoned pupils. Knowledge production about me and my position in the school was thus fluid and, to an extent, beyond my control, determined by the actions of the researched on and through my body.

Teachers generally positioned me as a colleague: I had previously worked as a teacher, shared a teachers' house on the campus, stood with teachers at assembly and worked in the staffroom. My position in the classroom was less clear. Although many suggest adults researching children should endeavour to 'cast aside the trappings of power afforded by age' (Valentine, 1999, p. 11), equal research relationships are impossible. I endeavoured to place myself in positions more equal with the students, and to give greater weight to their 'voices', than did their teachers. Attempting to adopt a 'least adult' role in research with children, however, neglects the fact that the researcher is inevitably seen/treated by children according to their own conception of child/adult relations (James et al., 1998). To have sought to be read as a student would have been impossible: age and education differentiated me from the young people, in an institution where prevalent discourses order social relations particularly by age and education. My role in class was generally 'observer-as-participant' (Jackson, 1983), sitting among the students, observing interaction. By 
sitting with the students in the classroom, I was arguably blurring discursively constructed boundaries. However, when students were engaged in individual or group activities I joined the teacher in moving around the class, giving help and marking work, and on several occasions taught classes myself. I bodily adopted the role of teacher, a role I could not easily avoid and one with which I felt comfortable.

Being perceived as a teacher reinforced the dominant discourses of the school and drew attention to my power relative to that of the students. This was reinforced when I was asked to invigilate an examination, towards the end of which a note was passed between two girls. Instinctively I took the note, exercising power over the students. A combination of circumstances - my prior experience of teaching, my assumption of a particular role in school, my placement by others in a particular role, the actions of the students - all contributed to an (involuntary) 'reflexive' action (see Nast 1998) which influenced my positioning in the school. The two girls approached me at the end of the examination and begged me not to report them. I had placed myself in a difficult position in terms of relationships with both students and teachers. Fine and Sandstrom (1988) point to problems caused by the presence of a non-disciplining adult, and the risks of undermining 'justice' within a school. Having promised the students nothing, I said nothing to the teachers.

This incident raises the question of whether I could, or should, have been engaged in 'undermining justice', supporting students when they resisted authority, and even undermining the institution of the school itself as an expression of Western dominance. My placement in the school was determined partly by my own performance of particular roles: roles that were partly (voluntarily and involuntarily) 'reflexive' responses to constraints imposed by the complex and dynamic power relations of the school, and the situations in which I was placed by others. The need to 'generate data' limited my options. While I exercised some influence independently in the school, I could not easily risk the relationships that sustained me there. I had little more lassitude to abandon my work in the school than those employed there. Even without these constraints, however, I felt an obligation to the headteacher who welcomed me into his school, and to the teachers who let me attend their lessons, and treated me as a friend and colleague. These individuals were not simply exploiters, to be undermined, but, themselves subject to relations of domination, resisted in various ways.

Participant observation is a two-way process: not only do we observe and participate in the lives of the researched, but they observe and participate in our lives. Regardless of how we choose to represent ourselves, we cannot completely control the ways our actions are read by others. A researcher will inevitably 
be read differently by men and women; headteacher, teachers and students. Equally, as the researched only perform/reveal partial identities in school or in focus groups, so I (can) only reveal partial truths about myself.

\section{Focus Groups}

To generate data on gender relations, I conducted focus groups with senior students. The focus group method assumes that knowledge is created through interaction (Krueger, 1988). It thus provides spaces for the production and transformation of discourses. The knowledge created would reach, not only a Western academic audience, but also the participating students. I was concerned, therefore, that among the immediate audience the knowledge created should subvert rather than support exploitative discourses, both of gender, and relating to other relations of domination associated with age and (post)colonial global relations.

Focus group participants exercise some power over the creation of knowledge, being able to influence the course of discussion, to choose what to say and to speak from experience (Dwyer, 1996; Goss and Leinbach, 1996). However, focus groups are embedded in wider power relations which structure knowledge production. Peer pressure discourages students from expressing strongly unconventional opinions (Valentine, 1999). The knowledge produced through focus groups most strongly reflects the views of more dominant participants (Stewart and Shamdasani, 1990). This dominance reflects personality, interest, competence in discussion and command of English, as well as other patterns of dominance and subordination between students. Lower stream students, for instance, participated much less than those from the upper stream. Although those with less apparent power can be encouraged, a stranger amid a group of acquaintances, cannot 'know all the dynamics that might have influenced the participants in the discussion' (Krueger, 1988, p. 165; see also Holbrook and Jackson, 1996). New discourses emerging from focus groups, then, are produced under relations of production that, to an extent, reflect existing patterns of dominance. This raises the question of whether they reinforce these patterns, a possibility that Mohan (1999) discusses in relation to the techniques of Participatory Rural Appraisal.

Gender has been observed to influence focus group interaction (e.g. Herod, 1993). For this reason, focus group discussions were conducted separately with girls and boys. This arguably reinforced the significance of gender as a category, undermining the school's effect of implying gender is irrelevant in many areas of life. ${ }^{4}$ Indeed, many students were perplexed and amused by the segregation. At the students' request, the last session brought girls and boys together. In this mixed group the views of the students on gender issues 
polarised. Paradoxically, the single sex groups had allowed differences to emerge between members of the same sex, which were obscured by the gender category that became all-important in the mixed group. It is not possible to determine which format was more reinforcing of the category of gender.

The existence of the focus groups was also an outcome of the wider postcolonial power relations underlying my presence in the field. While students opted in to the focus groups, and discussions were allowed to range quite freely, I, as moderator, undoubtedly influenced the course of the discussions and the 'knowledge' produced. Only to a limited extent, however, could I, as an educated Westerner, use this control to destabilise dominant knowledges about both gender relations in Zimbabwe, and the postcolonial relations which supported my own presence and position(s) in the school.

To destabilise the discourses that accorded me power relative to the students, and to recognise the agency of youth, I employed what James et al.. (1998) term an 'adult child model', treating the students as mature, competent persons. To have pretended to be neutral, or opted out of discussions, would have been to support the status quo, and also made myself appear aloof from the students. I therefore made it clear to the students that their views interested me, and were more important than my own, but challenged contradictions and inconsistencies, and their 'false' perceptions of 'the West'. The students were sophisticated debaters and willingly challenged me, or tried to win my support to one side or other of an argument. To seek to protect young people from challenging questions would deny their agency (James et al, 1998; Valentine, 1999). In fact, young people are often less bound by politeness and more ready to challenge the researcher than are adults (Valentine, 1999).

Inevitably, there were times when what I said lent support to calls for 'gender equality'. This carried the risk of reinforcing the common perception that 'equal rights' was a concept with origins in the West (and the dualistic converse, that 'inequality' was indigenous to Africa). My (inadvertent) affirmation of such perceptions could lead, either to a reverence for the superiority of Western thought, or to rejection of equality on the basis that such ideas are Western and imperialist. Instead I sought to undermine the view of students that 'in my culture' men and women were treated as equal. This required me to share stories from my own experience: stories, not of universal oppression of women, but of different forms of gender subordination, thereby seeking to undermine ideas of a universal path to gender equality. 
The use of English for discussion was problematic. Within the context of the school it was arguably appropriate, particularly as I was interested in the ways students mobilised the discourses of the school in discussions of gender. It gave students greater control over the research product than would have been the case had their voices been translated. Furthermore, it emphasised their facility with a second language relative to my lack of ability to speak their language. However, it reinforced the importance attached to speaking English, a practice that perpetuates the subordination of the formerly colonised (Ngugi wa Thiong'o, 1981), and prevents a critical approach to knowledge in the postcolonial Zimbabwean classroom by inhibiting spontaneous and free-ranging discussion.

It is impossible to know the lasting outcomes of the focus groups among the students. The focus groups, however, did allow the students an arena in which to produce new knowledges for an immediate audience as well as for a distant academic one. These discourses included the knowledge that students, too, can create knowledge, that young people have agency. Often the views to which the students gave voice were more oppositional to dominant gender discourses than those expressed by their parents and teachers. The focus groups also facilitated the production of new knowledges about 'First World women'. Nonetheless, the extent to which such discourses subvert existing relations of domination is tempered by the power relations in which the focus group is embedded, both those internal to the group, and, perhaps more fundamentally, those that place a Western researcher amid a group of Zimbabwean students.

\section{Student Compositions}

Another means of giving voice to the students/appropriating their knowledge/encouraging the production by students of new knowledge about Third World women was through asking students to write compositions. Story writing is a research method that exploits young people's particular talents, affording them greater control over the process than many methods (James et al., 1998). A choice of titles was offered, and students were able to express their thoughts and opinions as far as their English, the medium and time constraints allowed.

The exercise was shaped by my exploitation of the 'rule following behaviour' through which power is exercised, unobserved, in schools (Valentine, 1999). It was also constrained and shaped by the interests of various participants: I was able to elicit relatively 'authentic' student voices; the teachers were pleased to see their students occupied, and given practice in writing essays; the students wrote in the expectation of having their English 'corrected' by a native speaker. To have refused to provide this service would have seemed 
mean. While correcting obvious 'mistakes' in the students' English, I used the opportunity to express my interest in, and gratitude for, their contributions. Although according value to the thoughts and ideas and product of the students, I was affirming the value of English and the right of those who speak it as a first language to 'correct' the English of those for whom it is a second language.

This method of research enabled the generation of valuable data which arguably reflected, more than any of the other methods employed, the 'authentic' voices of the researched. However, it allowed little scope to the young people to create oppositional knowledges for consumption in the field and relied on relationships that reproduce dominant discourses of First World authority.

\section{Student Research}

Many researchers have advocated researching with, not on or for their subjects (in relation to young people, Matthews et al., 1998; Valentine, 1999). Gibson-Graham (1994) employed research subjects as interviewers and involved them in research design. Others have tried to integrate young people as active researchers. Alderson (1995) describes a Barnardos project that trained 16 year olds to interview younger children. I decided, with the co-operation of teachers, to teach senior students about research and research methods, and to ask them to engage in small research projects of their own on the subject of gender. While acknowledging the dangers of assuming 'participatory' research allows the researched a significant role in the construction of knowledge (Mohan 1999), the projects would allow the young people some degree of input into the research. It would enable their active participation in the production of knowledge about gender, while informing my own research in valuable ways.

Like the compositions, preparation took place in spare time after the examinations. Unlike the compositions, however, this exercise met with resistance. While students co-operated in the classroom, none carried out any research outside school. In the formal atmosphere of the school they were prepared to devote time to meeting my expectations of them (or at least to 'follow rules', even to the extent of fabricating 'results', 'analysis' and 'conclusions' to their research projects in the classroom). However, they limited my authority to the confines of the school fence. An exercise that I saw as empowering of the students was seen by them as an unreasonable imposition on their time. Instead, they re-made themselves through the exercise, by destabilising the dominant knowledge of the white person as authoritative. 
Ironically, the exercise allowed the students to assert their agency, though not in the way I had hoped. I had two options: I could have sought to assert authority, drawing upon and reinforcing dominant discourses of age, race etc. (It is interesting to conjecture whether the students' reaction would have been the same, had I been male.) As Barnett (1997:140) notes, however, 'the mobilisation of silence might be a means of articulating agency'. Finding the students' refusal to co-operate a reassuring exercise of agency, I allowed them to 'undermine my authority' by failing to 'produce homework'.

\section{Conclusions}

Research is widely acknowledged to be a process not so much of uncovering knowledge as constructing knowledge. The ethics of constructing knowledge about Third World women for (primarily) an audience of Western academics has been widely debated. However, knowledge creation takes place as much in the field as in the production of written texts. As Rose (1997, p. 315) comments: 'neither the researcher nor the researched remains unchanged through the research encounter ... Both negotiate their knowledges through it.' Researchers inevitably produce new knowledges in the field, and inevitably produce them with others. The process cannot therefore be fully controlled. We cannot conduct fully feminist research (Stacey, 1997) because we cannot control the interpretations others will make of our words and actions, and the uses to which these will be put, especially in a 'messy' field (be this a school, or another social context) in which there are many actors with different relations to the knowledge produced.

Despite these limitations, fieldwork offers some potential for shaping the production of new knowledges. Researchers make decisions concerning the framing of their research and choice of methods, which have consequences for the way in which discourses are produced and transformed through interactions between researcher and researched in the field. We cannot have full control over the discourses produced because they are inevitably produced under relations of production that, particularly when we conduct research as white adults among Zimbabwean youth, reflect existing patterns of dominance. Choices must be made, however, and although the consequences of these choices can neither be fully controlled nor fully known (even when the research is complete), some responsibility must be assumed for the potential outcomes.

Among the key decisions a researcher must make concerns the extent to which academic objectives should be compromised in pursuance of (political) objectives in the field. The production of data, even data that enables the writing of texts which destabilise dominant discourses of 'Third World women', can be at odds with the production (and consumption) of oppositional knowledges in the field. To conduct ethical research 
demands a negotiation between performing behaviours in the field that generate data for academic purposes, and behaviours that produce oppositional knowledge in the field. These two processes of knowledge production need not be dualistically opposed (indeed, multiple processes and audiences are involved, not simply two conflicting ones). One way forward might be to give greater priority in textual productions to oppositional knowledges that arise through the techniques we employ, rather than employing techniques in the expectation of generating pre-determined forms of data.

\section{Acknowledgements}

The fieldwork discussed here was funded by a Wingate Scholarship and a grant from the Dudley Stamp Memorial Fund. I am grateful to Elsbeth Robson, Heidi Nast and James Sidaway and to the anonymous referees for their helpful comments on earlier drafts of this paper. 


\section{References}

Alderson, Priscilla (1995) Listening to children: children, ethics and social research, London: Barnardos.

Ansell, Nicola (1999) Southern African secondary schools: places of empowerment for rural girls? Cases from Lesotho and Zimbabwe, unpublished PhD thesis, Keele University.

Barnett, C. (1997) 'Sing along with the common people': politics, postcolonialism and other figures, Environment and Planning D - Society and Space, 15, 137-54.

Batterbury, Simon (1994) Alternative affiliations and the personal politics of overseas research: some reflections, in: Robson, Elsbeth and Willis, Katie (eds.) Postgraduate fieldwork in developing areas: a rough guide, Developing Areas Research Group, IBG, Monograph 8, 60-89

Caputo, Virginia (1995) Anthropology's silent 'others': a consideration of some conceptual and methodological issues for the study of youth and children's cultures, in: Amit-Talai, Vered and Wulff, Helena (eds.) Youth cultures, London: Routledge 19-42.

Chambers, R. (1983) Rural development: putting the last first, Harlow: Longman.

Corbridge, Stuart (1998) Development ethics: distance, difference, plausibility, Ethics, Place and Environment, 1, 35-54.

Donovan, Jenny (1988) 'When you're ill you've gotta carry it': health and illness in the lives of black people in London, in: Eyles, John and Smith, David M. (eds.) Qualitative methods in human geography, Cambridge: Polity, 180-196.

Dwyer, Claire (1996) Using indepth discussion groups for exploring questions of identity: possibilities and pitfalls, Feminist geography and the geography of gender research methodologies day conference, Nottingham Trent University.

England, Kim V.L. (1994) Getting personal: reflexivity, positionality, and feminist research, Professional Geographer, 46, 80-9.

Fine, Gary Alan and Sandstrom, Kent L. (1988) Knowing children: participant observation with minors, Newbury Park: Sage.

Gibson-Graham, J.K. (1994) 'Stuffed if I know!' reflections on post-modern feminist social research, Gender, Place and Culture, 1, 205-24.

Gilbert, Melissa R. (1994) The politics of location: doing feminist research at 'home', Professional Geographer, 46, 90-6.

Goss, Jon D. and Leinbach, Thomas R. (1996) Focus groups as alternative research practice: experience with transmigrants in Indonesia, Area, 28, 115-23. 
Herod, Andrew (1993) Gender issues in the use of interviewing as a research method, Professional Geographer, 45, 305-16.

Holbrook, Beverley and Jackson, Peter (1996) Shopping around: focus group research in North London, Area, 28, 136-42.

Jackson, Peter (1983) Principles and problems of participant observation, Geografiska Annaler, 65 B, 29-46.

James, Allison, Jenks, Chris and Prout, Alan (1998) Theorising childhood, New York: Teachers College Press.

Katz, Cindi (1992) All the world is staged: intellectuals and the projects of ethnography, Environment and Planning D: Society and Space, 10, 495-510.

Katz, Cindi (1994) Playing the field: questions of fieldwork in geography, Professional Geographer, 46, 6772.

Keith, Michael (1992) Angry writing: (re)presenting the unethical world of the ethnographer, Environment and Planning D: Society and Space, 10, 551-68.

Kobayashi, Audrey (1994) Coloring the field: gender, 'race', and the politics of fieldwork, Professional Geographer, 46, 73-80.

Krueger, Richard A. (1988) Focus groups: a practical guide for applied research, Newbury Park: Sage.

Madge, Clare (1993) Boundary disputes: comments on Sidaway (1992), Area, 25, 299-300.

Madge, Clare (1994) Ethics of research in the Third World, in: Robson, Elsbeth and Willis, Katie (eds.) Postgraduate fieldwork in developing areas: a rough guide, Developing Areas Research Group, IBG, Monograph 8, 91-102.

Matthews, Hugh, Limb, Melanie and Taylor, Mark (1998) The geography of children: some ethical and methodological considerations for project and dissertation work, Journal of Geography in Higher Education, 22, 311-24.

McDowell, Linda (1997) Doing gender: feminism, feminists and research methods in human geography, in: McDowell, Linda and Sharp, Joanne P. (eds.) Space, gender, knowledge: feminist readings, London: Arnold, 105-114.

McDowell, Linda and Sharp, Joanne B. (eds.) (1997) Space, gender, knowledge: feminist readings, London: Arnold.

Mohan, Giles (1999) Not so distant, not so strange: the personal and the political in participatory research, Ethics, Place and Environment, 2, 41-54.

Nast, Heidi J. (1994) Opening remarks on 'Women in the field', Professional Geographer, 46, 54-66. 
Nast, Heidi J. (1998) The body as 'place': reflexivity and fieldwork in Kano, Nigeria, in: Nast, Heidi J. and Pile, Steve (eds.) Places through the body, London: Routledge, 93-116.

Ngugi wa Thiong'o (1981) Decolonising the mind: the politics of language in African literature, Harare: Zimbabwe Publishing House.

Pollard, Andrew (1985) Opportunities and difficulties of a teacher-ethnographer: a personal account, in: Burgess, Robert G. (ed.) Field methods in the study of education, Lewes: Falmer, 217-233.

Porter, Gina (1995) 'Third World' research by 'First world' geographers: an Africanist perspective, Area, 27, 139-41.

Radcliffe, Sarah A. (1994) (Representing) post-colonial women: authority, difference and feminisms, Area, 26, 25-32.

Ramazanoglu, Caroline (1992) On feminist methodology: male reason versus female empowerment, Sociology, 26, 207-12.

Robson, Elsbeth (1994) From teacher to taxi driver: reflections on research roles in developing areas, in: Robson, Elsbeth and Willis, Katie (eds.) Postgraduate fieldwork in developing areas: a rough guide, Developing Areas Research Group, IBG, Monograph 8, 36-59.

Rose, Gillian (1997) Situating knowledges: positionality, reflexivities and other tactics, Progress in Human Geography, 21, 305-20.

Shah, Alpa (1999) Power plays: reflections on the process of submitting an undergraduate dissertation, Area, 31, 307-12.

Sidaway, James Derrick (1992) In other worlds: on the politics of research by 'First World' geographers in the 'Third World', Area, 24, 403-8.

Sidaway, James Derrick (1997) The (re)making of the western 'geographical tradition': some missing links, Area, 29, 72-80.

Smith, David M. (1994) On professional responsibility to distant others, Area, 26, 359-67.

Spivak, Gayatri Chakravorty (1988) Can the subaltern speak?, in: Nelson, Cary and Grossberg, Larry (eds.) Marxism and the interpretation of culture, Urbana: University of Illinois Press, 271-313.

Stacey, Judith (1997) Can there be a feminist ethnography? in: McDowell, Linda and Sharp, Joanne (eds.) Space, gender, knowledge: feminist readings, London: Arnold, 115-123.

Staeheli, Lynn A. and Lawson, Victoria A. (1994) A discussion of 'Women in the field': the politics of feminist fieldwork, Professional Geographer, 46, 96-102.

Stewart, David W. and Shamdasani, Prem N. (1990) Focus groups: theory and practice, Newbury Park: Sage. 
Twyman, Chasca, Morrison, Jean and Sporton, Deborah (1999) The final fifth: autobiography, reflexivity and interpretation in cross-cultural research, Area, 31, 313-26.

Valentine, Gill (1999) Being seen and heard? The ethical complexities of working with young people at home and at school, Ethics, Place and Environment, 2, 141-155.

Valentine, Gill, Skelton, Tracey and Chambers, Deborah (1998) Cool places: an introduction to youth and youth cultures, in: Skelton, Tracey and Valentine, Gill (eds.) Cool places, London: Routledge, 1-32.

Varley, Ann (1996) Paralysis and power: making work with 'Third World' women possible, Feminist geography and the geography of gender research methodologies day conference. Nottingham-Trent University.

WGSG (1992) Feminists and feminism in the academy, Antipode, 24, 218-37.

WGSG (1997) Feminist geographies: explorations in diversity and difference, Harlow: Longman.

Widdowfield, Rebekah (2000) The place of emotions in academic research, Area, 32, 199-208.

\section{Endnotes}

${ }^{1}$ While recognising the inadequacy of any terms that seek to impose a common identity on diverse parts of the world, this paper employs the terms 'First World'/'West' and 'Third World', these being preferable to North/South which imply an apolitical dualism or developed/developing/underdeveloped which suggest an embrace of modernisation/dependency theory.

${ }^{2}$ I recognise that use of the terms 'us' and 'we' suggest a common subject position which will not be shared by all readers of this paper. I employ the terms to refer, as broadly as possible, to those from the 'First World' conducting academic research of critical intent in a 'Third World' context.

${ }^{3}$ This is not to say that there is an essential difference between 'African' and 'Western' ways of knowing, particularly given the (albeit asymmetrical) interaction between knowledge systems (Barnett, 1997; Sidaway, 1997), notably through schooling, over the past century.

${ }^{4}$ Similarly, Caputo (1995) has observed how research relationships with children can contribute to the production of childhood as a category. 